Norbert Radek - Renata Dwornicka

\title{
FIRE PROPERTIES OF INTUMESCENT COATING SISTEMS FOR THE ROLLING STOCK
}

This paper presents results of the experimental research aimed at fire and smoke properties of rolling stock coating system. The overriding research task was to meet current European requirements in the field of fire properties with maintaining the desired performance parameters, such as protective and decorative properties. The research determined parameters such as flame spreading over the surface and heat emission of coating system prepared on steel substrate. Research was carried out to find the optimum thickness of intumescent layer. The tests have shown the effectiveness of use of a protective paint that allows meeting the requirements in the field of fire safety.

Keywords: fire properties, flame propagation, heat emission, smoke properties, intumescent paint

\section{Introduction}

Coating systems for the rolling stock must fulfill mechanical, protective and decorative properties maintenance longer on the vehicle. These requirements include: adhesion, abrasion resistance, hardness, chemical resistance, resistance to weather conditions (humidity, UV, corrosion). Coating systems intended for the rolling stock in addition to the above-mentioned requirements, as well as ease of application, must also have adequate fire performance [1-3]. Strong emphasis on safety in railway transport caused intensive development of requirements and methods in this area and as a consequence contributed to development of materials and products. There was a research to develop new and modify existing materials used in rail vehicles, which reduce the risk of people being threatened and improve the overall safety. Table 1 presents requirements for the coating systems of the rolling stock, both inside (R1) and outside (R7). The coating systems for rail vehicles must meet as the minimum, the requirements specified by the HL2 hazard. An important effect of the existing fire (posing a deadly threat to passengers and impeding evacuation) is the spread of flame on the surface as a result of the combustion of materials used on railway vehicles [4]. The most important element of effective fire protection is use of the fire-resistant materials limiting the spread of fire and smoke in the rolling stock. However, values of the specified parameters CFE and MARHE were significantly different from the admissible criteria. Therefore, an intumescent layer was introduced into the system in order to limit the impact of the ignition source operation on the lower layers, especially on the putty. The effect of thickness of the intumescent layer on the fire and smoke properties of the entire system was determined.

\section{Experimental procedures}

All the tested coatings were applied to $1 \mathrm{~mm}$ thick S355 carbon steel plates with a SATA spray gun; prior to application the surface of steel was polished with 80-grit sandpaper. Coating systems consist of the following layers: anti-corrosion epoxy primer, putty, primer filler, basecoat and anti-graffiti clear coats BO100-AGR. Each layer is applied and dried in accordance with requirements of the technological cards. The prepared samples were conditioned at $23^{\circ} \mathrm{C}$ and $50 \%$ humidity for minimum 7 days in order to perform tests on dry coating. The thickest layer in the coating systems, applied to the external walls of rail vehicles is a putty. The above results from the desire to hide all inequalities and obtain the maximum flatness of the painted surface of the vehicle body shells.

To assess the fire resistance, these fire parameters were selected that characterize the material's resistance to external fire sources, i.e.:

1) CFE - Critical Flux at Extinguishment, $\mathrm{kW} / \mathrm{m}^{2}$ (the lower its value, the greater the fire hazard) according to ISO 5658-2 [6] (Figure 1).

2) The side flame spread test was performed by exposure of a vertically arranged sample to external heat flux with a standardized density distribution $\left(50 \mathrm{~kW} / \mathrm{m}^{2}\right)$. At the end of the test, the length of the burned part of the sample is determined and entered into the program to calculate the Critical Flux at Extinguishment CFE [kW/ $\mathrm{m}^{2}$ ] by the control program.

MARHE - maximum average rate of heat release $\mathrm{kW} / \mathrm{m}^{2}$ - (the higher its value, the greater the fire hazard), according to ISO 5660-1 [7] (Figure 2).

Measurements of maximum heat generated were made using a conical calorimeter using the oxygen consumption

\footnotetext{
Norbert Radek ${ }^{1, *}$, Renata Dwornicka ${ }^{2}$

${ }^{1}$ Faculty of Mechatronics and Mechanical Engineering, Kielce University of Technology, Poland

${ }^{2}$ Institute of Applied Informatics, Faculty of Mechanical Engineering, Cracow University of Technology, Poland

*E-mail of corresponding author: norrad@tu.kielce.pl
} 
Table 1 Numerical values for each test specified in EN 45545-2 [5]

\begin{tabular}{|c|c|c|c|c|}
\hline \multirow{2}{*}{ Parameter } & \multirow{2}{*}{ Requirement } & \multicolumn{3}{|c|}{ Values required for a specific HL threat } \\
\hline & & HL1 & HL2 & HL3 \\
\hline \multirow{4}{*}{$\begin{array}{c}\mathrm{CFE}\left(\mathrm{kWm}^{-2}\right) \\
\text { ISO } 5658-2\end{array}$} & \multirow{2}{*}{$\mathrm{R} 1, \mathrm{R} 7$} & $\geq 20$ & $\geq 20$ & $\geq 20$ \\
\hline & & $\mathrm{a}$ & $\mathrm{a}$ & $\mathrm{a}$ \\
\hline & \multirow{2}{*}{$\mathrm{R} 17$} & 13 & 13 & 13 \\
\hline & & $\mathrm{a}$ & a & $\mathrm{a}$ \\
\hline \multirow{2}{*}{$\begin{array}{l}\text { MARHE }\left(\mathrm{kWm}^{-2}\right) \\
\text { ISO } 5660-1\end{array}$} & $\mathrm{R} 1, \mathrm{R} 7, \mathrm{R} 17$ & $\mathrm{a}$ & $\leq 90$ & $\leq 60$ \\
\hline & $\mathrm{R} 8$ & - & $\leq 50$ & $\leq 50$ \\
\hline $\begin{array}{c}\quad \mathrm{D}_{\mathrm{s}}(4)(-) \\
\text { EN ISO 5659-2 }\end{array}$ & $\mathrm{R} 1$ & $\leq 600$ & $\leq 300$ & $\leq 150$ \\
\hline \multirow{2}{*}{$\begin{array}{c}D_{\mathrm{s}} \max (-) \\
\text { EN ISO 5659-2 }\end{array}$} & $\mathrm{R} 7, \mathrm{R} 8, \mathrm{R} 17$ & - & $\leq 600$ & $\leq 300$ \\
\hline & $\mathrm{R} 10$ & $\leq 600$ & $\leq 300$ & $\leq 150$ \\
\hline $\begin{array}{l}\mathrm{VOF}_{4}(\mathrm{~min}) \\
\text { EN ISO 5659-2 }\end{array}$ & $\mathrm{R} 1$ & $\leq 1200$ & $\leq 600$ & $\leq 300$ \\
\hline \multirow{2}{*}{$\begin{array}{c}\operatorname{CIT}_{G}(-) \\
\text { EN ISO 5659-2 }\end{array}$} & $\mathrm{R} 1, \mathrm{R} 17$ & $\leq 1.2$ & $\leq 0.9$ & $\leq 0.75$ \\
\hline & $\mathrm{R} 7, \mathrm{R} 8,10$ & - & $\leq 1.8$ & $\leq 1.5$ \\
\hline
\end{tabular}

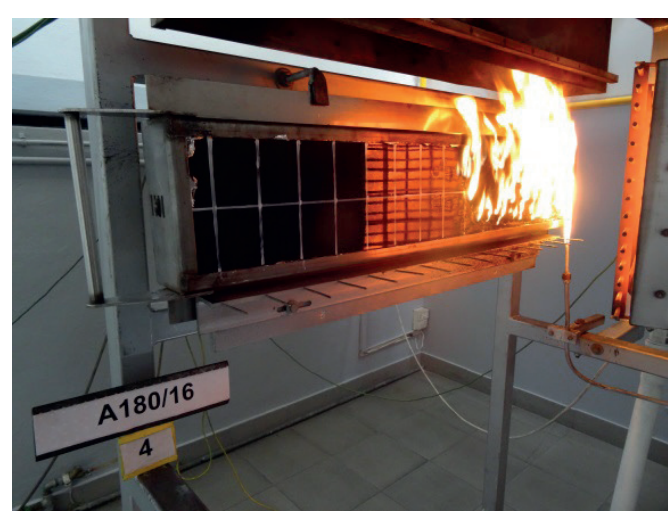

Figure 1 Determinationof Critical Flux at Extinguishment- CFE according to ISO 5658-2

calorimetry principle: For most materials per kilogram of oxygen consumed by burning material, 13.1 MJ of heat is released to within $\pm 5 \%$. Use of the precision oxygen measurement equipment in gas extraction and gas flow measurement in the extract, allow for a very precise determination of oxygen consumption and at the same time to accurately calculate the value of the released heat and its rate of release.

To assess the fire resistance, these further fire parameters were selected that characterize the material's resistance to external fire sources, as well, i.e.:

1) $\mathrm{D}_{\mathrm{s}}(\max )$ (maximum optical density of smoke) (-), Ds(4)

$(-)$ (specific optical density of smoke in the 4th min),

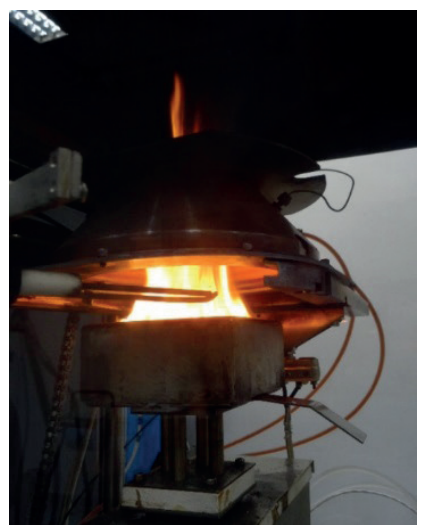

Figure 2 MARHE determination using a cone calorimeter according to ISO 5660-1

$\mathrm{VOF}_{4}$ (min) (blackout in the 4th min) - according to EN ISO 5659-2 [8] (Figure3).

2) The tests determining the optical density of smoke were carried out with a set thermal flow of $50 \mathrm{~kW} / \mathrm{m}^{2}$ without a pilot burner. The attenuation of the white light beam passing through the smoke was measured.

$\mathrm{CIT}_{\mathrm{G}}$ (Conventional Index of Toxicity determined in the 4th min and in 8 min) (-) - according to EN ISO 5659-2 [8] and EN 45545-2 [5] Annex C (Figure 3).

The toxicity tests were carried out with a given heat flux of $50 \mathrm{~kW} / \mathrm{m}^{2}$, no pilot burner, sampling at 4 and 8 minutes. The FTIR (Fourier Transform Infrared Spectroscopy) was used for the determination of gases. 

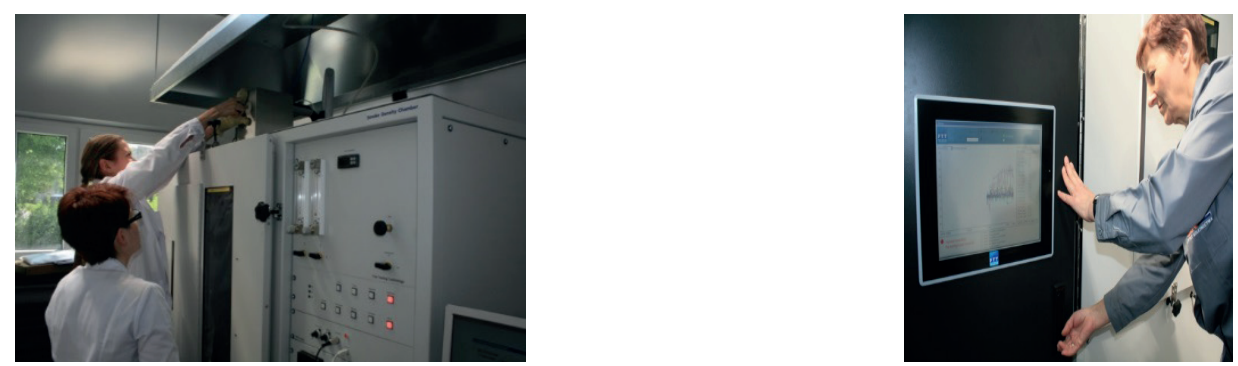

Figure 3 Determination of smoke properties using a smoke chamber according to EN ISO 5659-2 and a toxicity index when connected to the FTIR analyzer chamber (on the right) according to EN 45545-2 Annex C
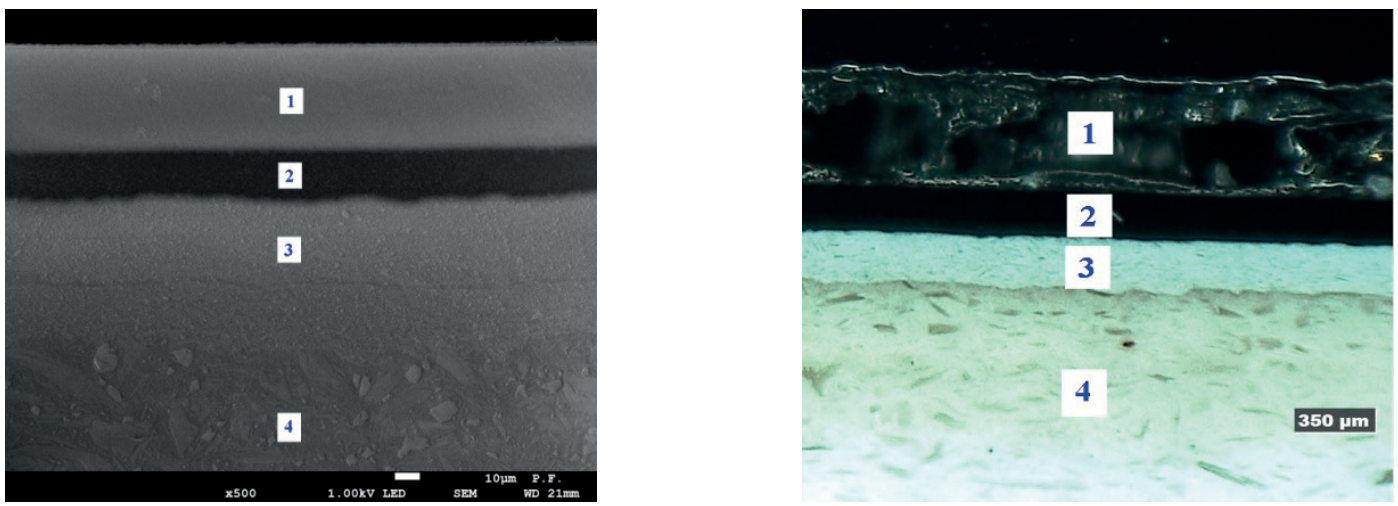

Figure 4 SEM (left) and LM (right) micrographs of the polished cross-section through a coating system on S355 carbon steel substrate: 1- clear coat, 2 - base coat, 3 - filler, 4 - putty

Table 2 Results of the flame spread test of the rolling stock coating system

\begin{tabular}{cccccc}
\hline Sample & Spread of flame (mm) & Burning time (s) & CFE $\left(\mathrm{kWm}^{-2}\right)$ & Mean CFE $\left(\mathrm{kWm}^{-2}\right)$ & $\begin{array}{c}\text { Standard deviation CFE } \\
\left(\mathrm{kWm}^{-2}\right)\end{array}$ \\
\hline 1 & 447 & 755 & 13.6 & & 1.1 \\
2 & 469 & 680 & 11.6 & 12.4 & \\
3 & 466 & 670 & 11.9 & & \\
\hline
\end{tabular}

The previous tests of the paint systems showed that the first two parameters were the most difficult to fulfill, so the tests were started from this two parameters [9-10]. The tests were performed at the Materials \& Structure Laboratory of the Railway Research Institute in Warsaw. In the next stage of the work, an intumescent layer was introduced into the system in order to limit the impact of the ignition source operation on the lower layers, especially on the putty. Then, further research was undertaken to determine the required thickness of the intumescent layer to meet requirements for the CFE. The tests were carried out for the thickness from 200 to $1000 \mu \mathrm{m}$.

\section{$3 \quad$ Results and discussion}

\subsection{Microstructure analysis}

A microstructure analysis was conducted for antigraffiti coating systems using the JEOL JSM-7100F scanning electron microscope with field emission and the Hirox KH-8700 light microscope.

Thickness of the obtained coating systems was from approx. 2300 to approx. $2500 \mu \mathrm{m}$. There are clear boundaries between the individual layers. Figure 4 shows the clear boundary between the varnish layers and the putty. Also, the varnish layers are free of pores and microcracks.

\subsection{Measurement of flammability properties}

The CFE test according to ISO 5658-2 is carried out on three samples with dimensions of $155 \mathrm{~mm} \times 800 \mathrm{~mm}$ $\mathrm{x} 1.5 \mathrm{~mm}$. This method involves exposed the vertical sample to an external heat stream with a standard density distribution. Results of the test are presented in Table 2.

Samples with an anti-graffiti coating system were treated with a cone-shaped electric radiator with a radiation intensity of $50 \mathrm{~kW} / \mathrm{m}^{2}$. The ignition was initiated by the spark and combustion was carried out in air atmosphere $\left(0.024 \mathrm{~m}^{3} / \mathrm{s}\right)$. Classification according to EN 45545-2 defines the MARHE parameter, which represents the maximum average rate of heat release (ARHE) over a 20 minute test. The ARHE value is calculated according to the following formula:

$\operatorname{ARHE}\left(t_{n}\right)=\frac{\sum_{2}^{n}\left(t_{n}-t_{n-1}\right) \times \frac{q_{n}+q_{n-1}}{2}}{t_{n}-t_{n-1}}$, 
Table 3 Results of the maximum average heat release of the rolling stock coating system

\begin{tabular}{|c|c|c|c|}
\hline Sample & MARHE $\left(\mathrm{kWm}^{-2}\right)$ & Mean value of MARHE $\left(\mathrm{kWm}^{-2}\right)$ & Standard deviation MARHE $\left(\mathrm{kWm}^{-2}\right)$ \\
\hline 1 & 208.1 & \multirow{3}{*}{198.1} & \multirow{3}{*}{9.4} \\
\hline 2 & 196.8 & & \\
\hline 3 & 189.4 & & \\
\hline
\end{tabular}

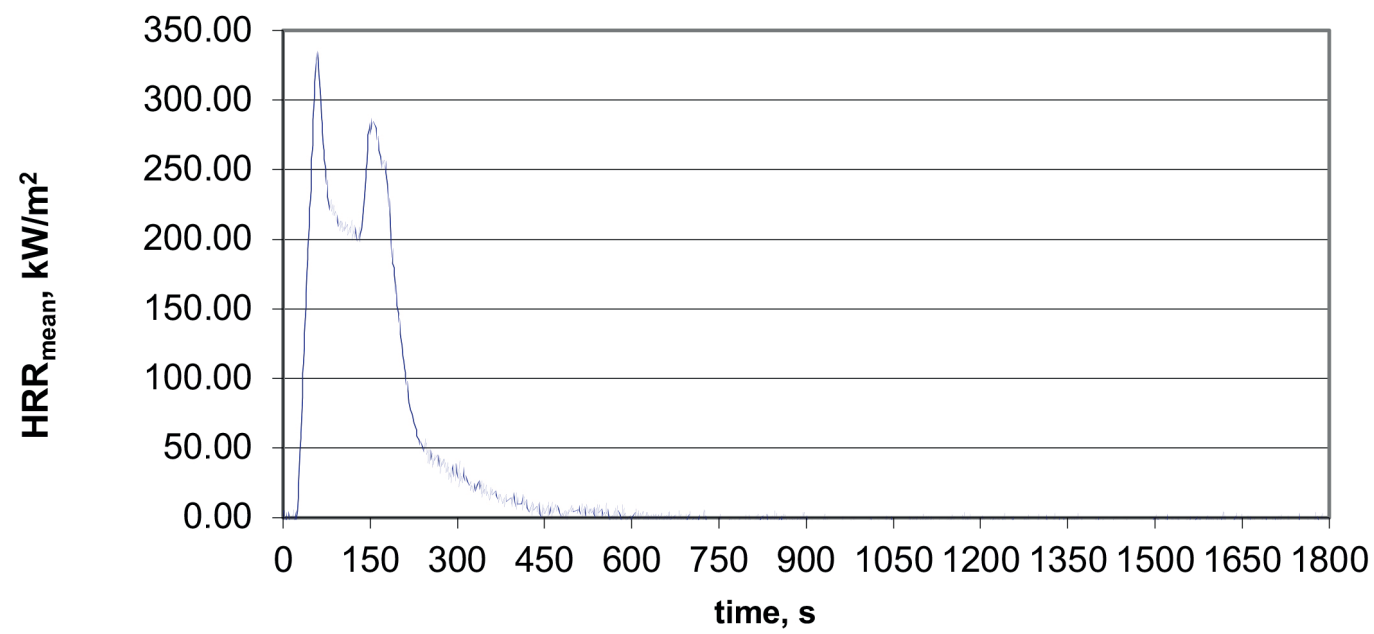

Figure 5 Example of the HRR heat releasing curve for the coating system

25
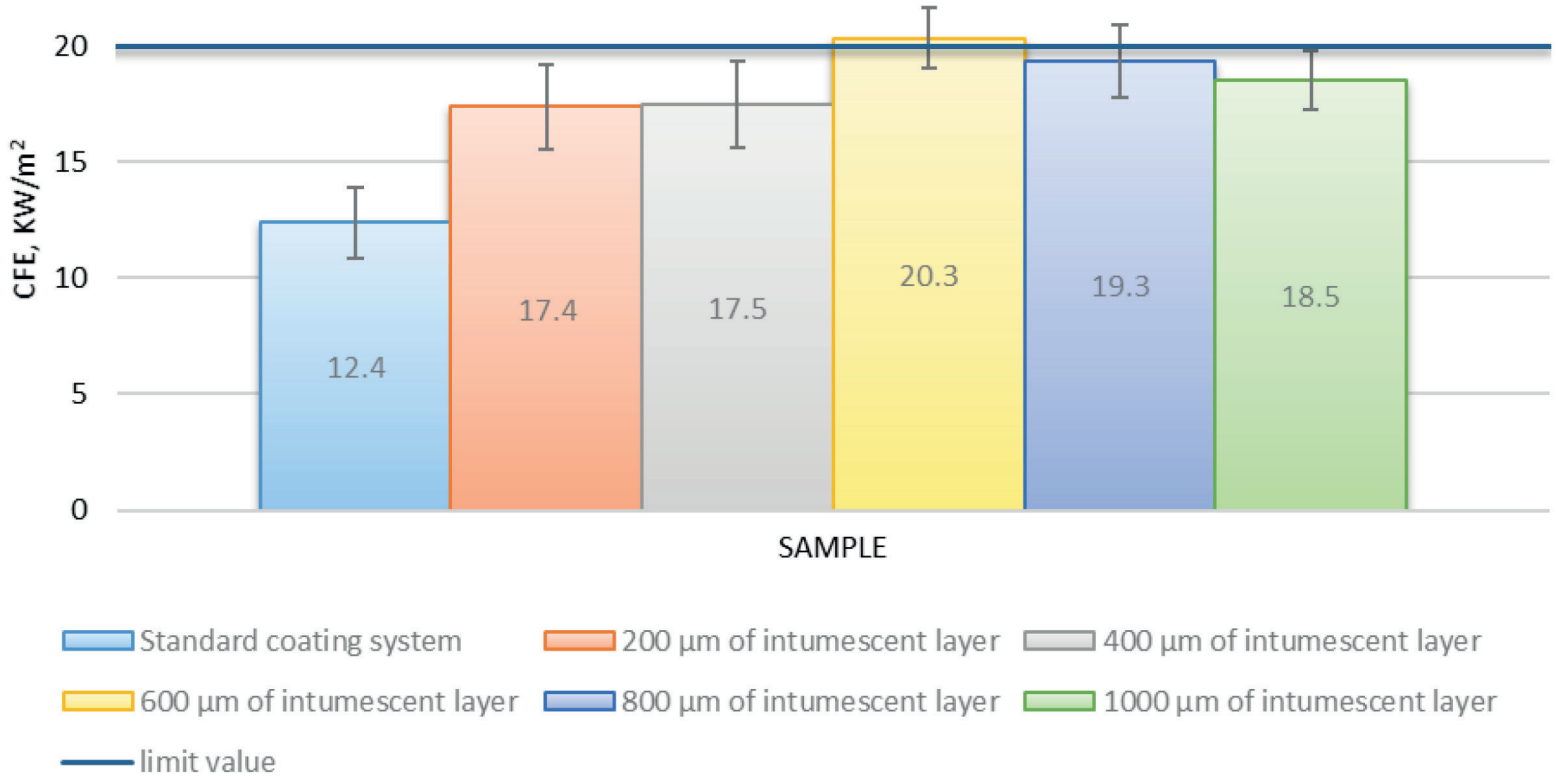

Figure 6 Results of the critical heat flux of the coating system after applying a fire protection layer of varying thickness

where:

$t$-time, mostly $t_{1}=0$,

$q$ - the rate of heat release, mostly $q_{1}=0$.

The test is carried out according on three weighted sample of dimension $100 \mathrm{~mm} \times 100 \mathrm{~mm} \times 1 \mathrm{~mm}$. The test result are presented in Table 3. The Figure 5 presents example of the heat release rate curve (HRR) depending on the energy emitted from a specific surface to duration of the test.
Result sof the conducted tests definitely differed from requirements of the EN 45545-2 standard. Thickness of each layers (mostly putty) had a significant influence on results of the fire properties. The newly developed protective layer (intumescent layer) was designed to improve the flammability, while maintaining durability of the coating system. Intumescent layer, developed by Barwa laboratory, was tested in scope of impact its thickness on fire and smoke properties. The purpose of using the intumescent layer was to slow down the spread of fire, reduce the 


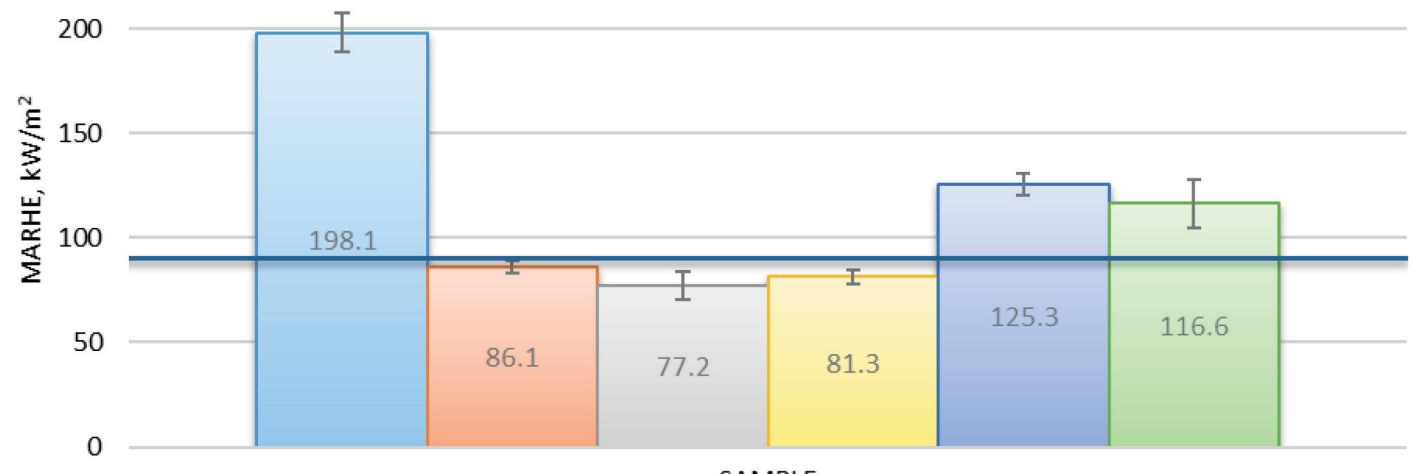

SAMPLE

$\square$ Standard coating system $\square 200 \mu$ m of intumescent layer $\square 400 \mu$ m of intumescent layer $\square 600 \mu \mathrm{m}$ of intumescent layer $\square 800 \mu \mathrm{m}$ of intumescent layer $\square 1000 \mu \mathrm{m}$ of intumescent layer - limit value

Figure 7 Results of the maximum average heat release of the coating system after application of a fire-resistant layer of varying thickness

350.00

300.00

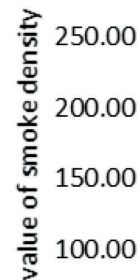

50.00 0.00

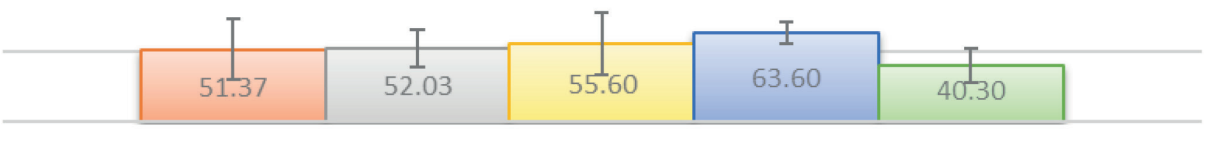

SAMPLE

$\square 200 \mu \mathrm{m}$ of intumescent layer $\square 400 \mu \mathrm{m}$ of intumescent layer $\square 600 \mu \mathrm{m}$ of intumescent layer $\square 800 \mu \mathrm{m}$ of intumescent layer $\square 1000 \mu \mathrm{m}$ of intumescent layer — limit value

Figure 8 Smoke optical density at 4 minutes of the coating system test with an intumescent layer

2.1000

1.8000

1.5000

崖 1.2000

2

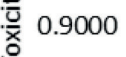

0.6000

0.3000

0.0000

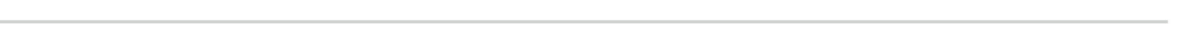

0.0000

$\square 800 \mu \mathrm{m}$ of intumescent layer $\square 1000 \mu \mathrm{m}$ of intumescent layer — limit value

Figure 9 Toxicity results of a coating system with an intumescent layer at the 8th minute of the test 
amount of heat released and reduce the fumes emitted during the burning of the coating.

The mean values of the next thicknesses of the intumescent layer were compared to the initial results for the parameter of the Critical Flux at Extinguishment CFE (Figure 6) and for the parameter of the maximum average heat release MARHE (Figure 7). Studies of the CFE and MARHE parameters confirmed the beneficial properties of applying a protective layer to coating systems. In addition, thickness of the fire protection layer was determined, which translated into the best results. Both in the study determining the fire spreading parameter and the maximum average heat release, the most preferred thickness of the intumescent layer was about $600 \mu \mathrm{m}$ thickness. In the next investigated case, with a thickness of $800 \mu \mathrm{m}$ of intumescent layer, both parameters assumed less desirable values in relation to requirements of the EN 45545-2 standard.

\subsection{Smoke properties}

A large volume of smoke can limit visibility and confuse passengers at a time when every second is important. Another aspect is also the toxicity of smoke. Toxic gases cause poisoning and long health treatment. Therefore, use of agents from the group of halogens and bromides as flame retardants are not recommended. The coating system with an intumecent layer of various thicknesses was measured. Samples were prepared according to a technological process. The samples dimensions were $75 \mathrm{~mm} \times 75 \mathrm{~mm} \times$ $1 \mathrm{~mm}$. The tests were carried out together with the smoke analysis determining the toxic substances contained in it. Figure 8 shows results of the optical smoke density in the 4th minute of the test for different thicknesses of the intumescent coating included in the coating system.

$$
C I T_{G}=\frac{0.51 m^{3} \times 0.1 m^{2}}{150 m^{3} \times 0.004225 m^{2}} \times \sum_{i=1}^{i=8} \frac{c_{i}}{C_{i}},
$$

where:

$0.1 \mathrm{~m}^{2}$ - surface area of burning sample,

$150 \mathrm{~m}^{3}$ - the gaseous effluents disperse into standard vehicle volume,

$0.51 \mathrm{~m}^{3}$ - smoke chamber volume,

$0.004225 \mathrm{~m}^{2}$ - the exposed surface area of the test specimen, $c_{i}$ - the concentration measured in $\mathrm{mg} / \mathrm{m}^{3}$ of the $\mathrm{i}$-th gas in the EN ISO 5659-2 smoke chamber,

$C_{i}$ - the reference concentration measured in $\mathrm{mg} / \mathrm{m}^{3}$ of the i-th gas.
To assessthe toxicity of materials used in the railway industry, a standard toxicity index, calculated based on the obtained data, was introduced. The tests should determine the presence and concentration of eight substances in the gases from the burning sample. The gases were: $\mathrm{CO}_{2}, \mathrm{CO}$ $\mathrm{HF}, \mathrm{HCl}, \mathrm{HBr}, \mathrm{HCN}, \mathrm{SO}_{2}, \mathrm{NO}_{\mathrm{x}}(\mathrm{NOx}$ as the sum of $\mathrm{NO}$ and $\mathrm{NO}_{2}$ ). Conventional Index of Toxicity for generic products $\mathrm{CIT}_{\mathrm{G}}$ is calculated according to Equation (2).

Both in the 4 and 8 minute gas sampling each of the tested coating systems was characterized by negligible values of the general toxicity parameter. Figure 9 presents the results of the general toxicicty in the 8th minute sampling.

Thickness of the intumescent layer did not influence the value of the optical smoke density of the coating system at the 4th minute of the test and results obtained were within limits of measurement error. The obtained results deviated significantly from the value required by the EN 45545-2 standard. The results obtained in the measurement of smoke properties met the requirements of the EN 45545-2 standard, for each thickness of the applied intumescent layer in the coating system. There was no correlation between the thickness of the intumescent layer of coating systems and values obtained in smoke measurements and toxicity.

\section{Conclusions}

Tested coating system has homogeneous structure and is free of defects. Laboratory tests confirmed the positive effect of the intumescent layer on flammable properties of the coating system. The tests determined the optimal thickness of the protective layer of $600 \mu \mathrm{m}$. Deterioration of the flammability characteristics, when increasing the intumescent layer (above $600 \mu \mathrm{m}$ ), can be explained by delivery of a combustible substance to the system in the form of a polyurethane resin, which ensured the appropriate structure of this layer. Use of the intumescent layer in coating system allows to meet the requirements of the EN 45545-2 standard and apply the developed coating system in the production of rolling stock. Use of an intumescent layer does not have the negative effect on the smoke emission during a fire. No additional toxic gases are emitted during the fire compared to a standard coating system. The next step will be tests of resistance to aggressive environmental factors and corrosion resistance.

\section{References}

[1] RADZISZEWSKA-WOLINSKA, J. Fire properties of anticorrosion coatings to rolling stock. Czasopismo Techniczne [online]. 2016, 3, p. 79-86. ISSN 0011-4561. Available from: https://doi 10.4467/2353737XCT.16.124.5735

[2] RADEK, N., PASIECZYNSKI, L., MAKRENEK, M., DUDEK, A. Mechanical properties of anti-graffiti coating systems used in the railway industry. Materials Research Proceedings [online]. 2018, 5, p. 243-247. ISSN 2474-3941. Available from: https:// dx.doi.org/10.21741/9781945291814-43 
[3] PASIECZYNSKI, L., RADEK, N., KLONICA, M., KAMINSKI, J., SWIDERSKI, J. Properties of BO100-AGR clearcoat anti-graffiti coating systems used in the railway industry. Materials Research Proceedings [online]. 2018, 5, p. $225-230$. ISSN 2474-3941. Available from: https:// dx.doi.org/10.21741/9781945291814-40

[4] RADZISZEWSKA-WOLINSKA, J. Development of requirements for fire protection of rolling stock in Poland and its comparison with EN 45545. Problemy Kolejnictwa. 2013, 57(160), p. 109-119. ISSN 0552-2145.

[5] PN EN 45545-2 Railway applications - fire protection in rail vehicles. Part 2: requirements for materials and components for flammable properties.

[6] ISO 5658-2:2006 Reaction to fire tests - spread of flame. Part 2: lateral spread on building and transport.

[7] ISO 5660-1 Reaction-to-fire tests - heat release, smoke production and mass loss rate. Part 1: heat release rate (cone calorimeter method).

[8] EN ISO 5659-2 Plastics - smoke generation. Part 2: determination of optical density by a single-chamber.

[9] PASIECZYNSKI, L., RADEK, N., RADZISZEWSKA-WOLINSKA, J. Operational properties of anti-graffiti coating systems for rolling stock. Advances in Science and Technology Research Journal [online]. 2018, 12(1), p. 127-134. ISSN 2299-8624. Available from: https://doi: 10.12913/22998624/85705

[10] RADZISZEWSKA-WOLINSKA, J., RADEK, N., PASIECZYNSKI, L. Fire properties of "anti-graffiti" coating systems for rolling stock. In: 11th International Scientific and Technical Conference on Automotive Safety : proceedings. 2018. ISBN 978-1-5386-4579-6, p. 1-5. 